Archives of Gerontology and Geriatrics

Volume 58, Issue 3, May-June 2014, Pages 420-426

\section{Long-term food restriction prevents aging-associated sphingolipid turnover dysregulation in the brain}

Nataliya A. Babenko 이, Elena G. Shakhova

田 Show more

https://doi.org/10.1016/j.archger.2013.12.005

Get rights and content

\section{Abstract}

Abnormalities of sphingolipid turnover in the brain during normal aging and age-related neurological disorders were associated with the neurons loss and cognitive malfunction. Calorie restriction (CR) prevented age-related deficits in hippocampal long-term potentiation and improved cognitive function at old age. In the paper we investigated the ceramide and sphingomyelin (SM) levels in the brain regions, which are critical for learning and memory of 3- and 24-month-old rats, as well as the correction of sphingolipid turnover in the brain of old rats, by means of the CR diet and modulators of SM turnover. Using the [methyl- ${ }^{14} \mathrm{C}$ choline]SM, the neutral, but not the acid SMase activity has been observed to increase in both the hippocampus and brain cortex of 24-month-old rats with respect to 3-month-old animals. Age-dependent changes of neutral SMase activities were associated with ceramide accumulation and SM level drop in the brain structures studied. Treatment of the rats with the $\mathrm{CR}$ diet or $\mathrm{N}$-acetylcysteine (NAC) or a-tocopherol acetate, but not an inhibitor of acid SMase imipramine, reduced the ceramide content and neutral SMase activity in the hippocampus of 24-month-old animals with respect to control rats of the same age. These results suggest that redox-sensitive neutral SMase plays important role in SM turnover dysregulation in both the hippocampus and neocortex at old age and that the CR diet can prevent the age-dependent accumulation of ceramide mainly via neutral SMase targeting

$<$ Previous article in issue

Next article in issue
Modulation of sphingolipid metabolism with calorie. The Journal of Nutritional Biochemistry, Volume 26, Iss. Z Purchase PDF View details $v$

Effect of tooth pulp and periaqueductal central gra. . Brain Research, Volume 1382, 2011, pp. 19-28

- Purchase PDF View details $v$

Ceramide and neurodegeneration: Susceptibility $0 .$. Journal of the Neurological Sciences, Volume 278, Iss.

- Purchase PDF View details $\vee$

$<$ Previous 12

Citing articles (24)

Article Metrics

Captures

Exports-Saves:

Readers:

Mentions

Blog Mentions:

Citations

Citation Indexes:

¿̈PLUmx

\title{
Keywords
}

Aging; Brain; Sphingomyelin turnover; Calorie restricted diet; $\mathrm{N}$-acetylcysteine; $\mathrm{a}$-Tocopherol acetate 